\title{
Quarterly Management Document - FY16, 3rd Quarter, Physics-based Creep Simulations of Thick Section Welds in High Temperature and Pressure Applications
}

Thomas Lillo

August 2016

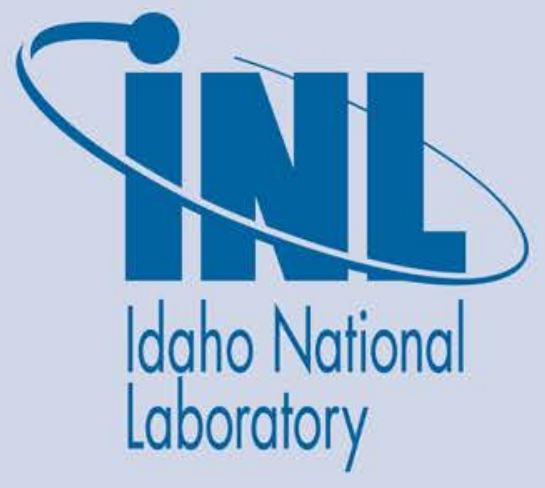

The INL is a U.S. Department of Energy National Laboratory operated by Battelle Energy Alliance 
INL/EXT-16-39551

\section{Quarterly Management Document - FY16, 3rd Quarter, Physics-based Creep Simulations of Thick Section Welds in High Temperature and Pressure Applications}

Thomas Lillo

August 2016

Idaho National Laboratory

Idaho Falls, Idaho 83415

http://www.inl.gov

Prepared for the

U.S. Department of Energy

Assistant Secretary for __, OR Office of

Under DOE Idaho Operations Office

Contract DE-AC07-05ID14517 
Quarterly Management Document - FY16, $3^{\text {rd }}$ Quarter, Physics-based Creep Simulations of Thick Section Welds in High Temperature and Pressure Applications

Document \# INL/EXT-16-39551

\begin{tabular}{|c|c|c|c|c|}
\hline $\begin{array}{l}\text { WBS Element } \\
\text { C.B.10.02.02.40 }\end{array}$ & $\begin{array}{l}\text { Project Title } \\
\text { Physics-based Creep Simulations of } \\
\text { Thick Section Welds in High } \\
\text { Temperature and Pressure } \\
\text { Applications }\end{array}$ & $\begin{array}{l}\text { Contract Numbe } \\
\text { FEAA90 }\end{array}$ & \begin{tabular}{|l|} 
Contract Start \\
$06 / 01 / 15$
\end{tabular} & $\begin{array}{l}\text { Contract End } \\
09 / 30 / 2016\end{array}$ \\
\hline \multicolumn{2}{|c|}{$\begin{array}{l}\text { Performer Name and Address } \\
\text { Thomas Lillo } \\
\text { Idaho National Laboratory } \\
\text { P.O. Box } 1625 \\
\text { Idaho Falls, ID } 83415\end{array}$} & & \multicolumn{2}{|c|}{$\begin{array}{l}\text { Principal Investigator(s) } \\
\text { Thomas Lillo }\end{array}$} \\
\hline
\end{tabular}

BUDGET AND COST REPORT

\begin{tabular}{|c|c|c|c|c|c|c|c|c|c|c|c|c|}
\hline \multicolumn{4}{|c|}{ Prior Year Funds (\$K) } & 148 & & & & & & & & \\
\hline \multicolumn{4}{|c|}{ Total Current Year Commitment (\$K) } & 398 & & & & & & & & \\
\hline \multicolumn{4}{|c|}{ Projected Current Year Costs (\$K) } & 305 & & & & & & & & \\
\hline & 0 & $N$ & D & $\mathrm{J}$ & $F$ & $M$ & $\mathbf{A}$ & $M$ & $\mathrm{~J}$ & $\mathrm{~J}$ & $\mathbf{A}$ & $s$ \\
\hline Planned Costs & 34 & 34 & 80.4 & 25 & 25 & 25 & 25 & 32 & 21 & & & \\
\hline Actual Costs & 40.2 & 81.9 & 17.0 & 3.5 & 0 & 32 & 42 & 16 & 27 & & & \\
\hline Variance & -6.2 & -47.9 & 63.4 & 21.5 & 25 & -7.0 & -17 & -16 & -6 & & & \\
\hline
\end{tabular}

MILESTONE REPORT

\begin{tabular}{|c|l|l|l|c|}
\hline $\begin{array}{c}\text { Milestone } \\
\text { Designation }\end{array}$ & \multicolumn{1}{|c|}{ Milestone Description } & Due Date & $\begin{array}{c}\text { Revised Due } \\
\text { Date }\end{array}$ & $\begin{array}{c}\text { Completion } \\
\text { Date }\end{array}$ \\
\hline A & Evaluate current MOOSE capabilities & $09 / 30 / 2015$ & & $09 / 30 / 2015$ \\
\hline B & Complete Alloy 617 weld characterization & $10 / 30 / 2015$ & & $11 / 18 / 2015$ \\
\hline C & Receipt of Alloy 740H plates & $10 / 30 / 2015$ & & $11 / 05 / 2015$ \\
\hline D & Complete welds in Alloy 740H & $11 / 16 / 2015$ & $7 / 31 / 2016$ & \\
\hline E & Characterize Alloy 740H welds & $02 / 01 / 2016$ & $09 / 30 / 2016$ & \\
\hline F & Creep model development - Stage 1 & $09 / 30 / 2016$ & & \\
\hline
\end{tabular}

TECHNICAL HIGHLIGHTS 
Milestone D, “Welding procedure development”

The weld for ASME qualification failed the qualification test. The results of the tensile testing and locations of the tensile bars in the original welded plate are shown in Table 1 and Figure 1, respectively. The tensile bars were flat, dog-bone specimens. There were 6 tensile bars that interrogated the tensile properties of the weld from the top of the plate all the way to the bottom of the plate. There were two batches of six tensile bars (labeled with prefix T1 and T2 in Table 1) from different locations in the plate as indicated in Fig. 1. There were 4 bend bars from four different locations in the plate also as indicated in Fig. 1. (It was planned to make creep specimens out of the remaining material as indicated in Fig. 1 but due to the failure of the qualification this is now being reconsidered.)

ASME Code Case 2702-1 for welding Alloy 740H indicates a minimum tensile strength of 150 ksi for the tensile bars taken from the weld. The values of the ultimate strength in Table 1 indicate all tensile bars past this criteria except one, circles in red. However, it is evident that the bottom of the weld exhibits a lower tensile strength than the upper portions of the welded plate.

Table 1. Results of Tensile Testing

\begin{tabular}{|c|c|c|c|c|c|c|c|c|c|}
\hline $\begin{array}{l}\text { Specimen } \\
\text { Identification }\end{array}$ & $\begin{array}{c}\text { Avg. } \\
\text { Thicknessa } \\
(\mathrm{mm})\end{array}$ & $\begin{array}{l}\text { Avg. Width } \\
(\mathrm{mm})\end{array}$ & $\begin{array}{c}\text { Cross-section } \\
\text { Area } \\
\left(\mathrm{mm}^{2}\right)\end{array}$ & $\begin{array}{c}\text { Crosshead } \\
\text { Speed } \\
\text { (mm/min) }\end{array}$ & $\begin{array}{l}\text { Max. Force } \\
(\mathrm{KN})\end{array}$ & $\begin{array}{c}\text { Ultimate } \\
\text { Strength } \\
\text { (ksi) }\end{array}$ & $\begin{array}{c}\text { Ultimate } \\
\text { Strength } \\
(\mathrm{MPa})\end{array}$ & $\begin{array}{l}\text { Type of } \\
\text { Failure }\end{array}$ & $\begin{array}{c}\text { Failure } \\
\text { Locationd }\end{array}$ \\
\hline T1-1 & 5.22 & 19.06 & 99.49 & 2 & 113.86 & 165.4 & 1140.4 & & In weld \\
\hline T1-2 & 5.28 & 19.03 & 100.48 & 2 & 116.61 & 168.3 & 1160.5 & & In weld \\
\hline T1-3 & 5.29 & 19.02 & 100.62 & 2 & 119.26 & 171.9 & 1185.3 & & In weld \\
\hline T1-4 & 5.25 & 19.00 & 99.75 & 2 & 119.94 & 174.4 & 1202.4 & & In weld \\
\hline T1-5 & 4.90 & 19.02 & 93.20 & 2 & 99.797 & 155.3 & 1070.8 & & In weld \\
\hline T1-6 & 5.22 & 19.02 & 99.28 & 2 & 95.162 & 109.0 & 958.48 & & In weld \\
\hline $\begin{array}{c}\text { Specimen } \\
\text { Identification }\end{array}$ & $\begin{array}{c}\text { Avg. } \\
\text { Thicknesså } \\
(\mathrm{mm})\end{array}$ & $\begin{array}{l}\text { Avg. Width } \\
(\mathrm{mm})\end{array}$ & $\begin{array}{c}\text { Cross-section } \\
\text { Area } \\
\left(\mathrm{mm}^{2}\right)\end{array}$ & $\begin{array}{l}\text { Crosshead } \\
\text { Speed } \\
(\mathrm{mm} / \mathrm{min})\end{array}$ & $\begin{array}{l}\text { Max. Force } \\
(\mathrm{KN})\end{array}$ & $\begin{array}{c}\text { Ultimate } \\
\text { Strength } \\
\text { (ksi) }\end{array}$ & $\begin{array}{l}\text { Ultimate } \\
\text { Strength } \\
(\mathrm{MPa})\end{array}$ & $\begin{array}{l}\text { Type of } \\
\text { Failure }\end{array}$ & $\begin{array}{l}\text { Failure } \\
\text { Locationd }\end{array}$ \\
\hline T2-1 & 5.40 & 19.10 & 103.14 & 2 & 120.39 & 169.3 & 1167.3 & & In weld \\
\hline T2-2 & 5.16 & 19.11 & 98.61 & 2 & 115.85 & 170.4 & 1174.9 & & In weld \\
\hline T2-3 & 5.28 & 19.11 & 100.90 & 2 & 120.14 & 172.7 & 1190.7 & & In weld \\
\hline T2-4 & 5.30 & 19.10 & 101.23 & 2 & 121.55 & 174.2 & 1200.8 & & In weld \\
\hline T2-5 & 5.25 & 19.12 & 100.38 & 2 & 106.1 & 153.3 & 1057 & & In weld \\
\hline T2-6 & 5.42 & 19.09 & 103.47 & 2 & 107.94 & 151.3 & 1043.2 & & In weld \\
\hline
\end{tabular}

The results of the bend tests are shown in Fig. 2. (Only 2 of the bend bars were correctly tested using the 4T radius (where $\mathrm{T}=$ thickness). However, these also showed failure at the bottom of the weld in the form of cracks. However, it should be noted that the crack was arrested as it propagated toward the top of the weld. So it is again evident that the bottom of the weld is deficient while the top of the weld exhibited the expected/desired properties which would have satisfied the ASME weld qualification.

These results indicate either issues with joint design or welding behavior during the first passes on the weld. Previous discussions with Special Metals indicated that industry is moving toward the "narrow groove" design for the reasons indicated in Fig. 3. Basically, considerable savings of time and filler metal can be achieved with the narrow groove design. Therefore, it was felt this was the most relevant design and the design shown in Fig. 4 was used in this work. The weld was completed using existing equipment, and as indicated in Fig. 4, the electrode was extended to reach the bottom of the weld for the initial passes. After evaluation of the mechanical property results and the microstructural results presented in the next section, it is thought that this welding arrangement suffered from an inadequate amount of cover gas and potentially a concave weld bead which tends to promote cracking on solidification and cooling, Fig. 5 . These cracks may not all be re-liquified during the next weld pass resulting crack defects in the weld. Additionally the base metal plates were not exactly flat and exhibited some warpage from rolling to our requested thickness. This 
warpage may have contributed to the cover gas issue by letting it escape the groove. In any case, these defects ultimately caused the failure in the bend tests, Fig. 2, and the poor tensile properties in Table 1.

The most cost-effective remedy was to redesign the weld groove. A design similar to that shown in Fig. 6 has been extensively at INL in welding of ni-based alloys, specifically Alloy 617. This weld design resulted in sound welds that easily passed ASME weld qualification. It is closely related to the dimensions in the upper portion of the narrow groove design illustrated in Fig. 4 and the design in Fig. 6 had performed well in the past, a decision was made to abandon the narrow groove design with ASME weld qualification and use the old weld joint design to produce welded joints so creep specimens could be made and creep tests started which is more important to the project at this time. (Some creep specimens will be made from the top portion of the narrow groove welds since this material essentially passed, or would have passed, the ASME weld qualification based on the tensile and bend behaviors of this portion of the welded plates with narrow grooves.) Three welded plates with this weld groove design are expected to be completed by the early part of the fourth quarter.

740 qualification plate suggested cuts

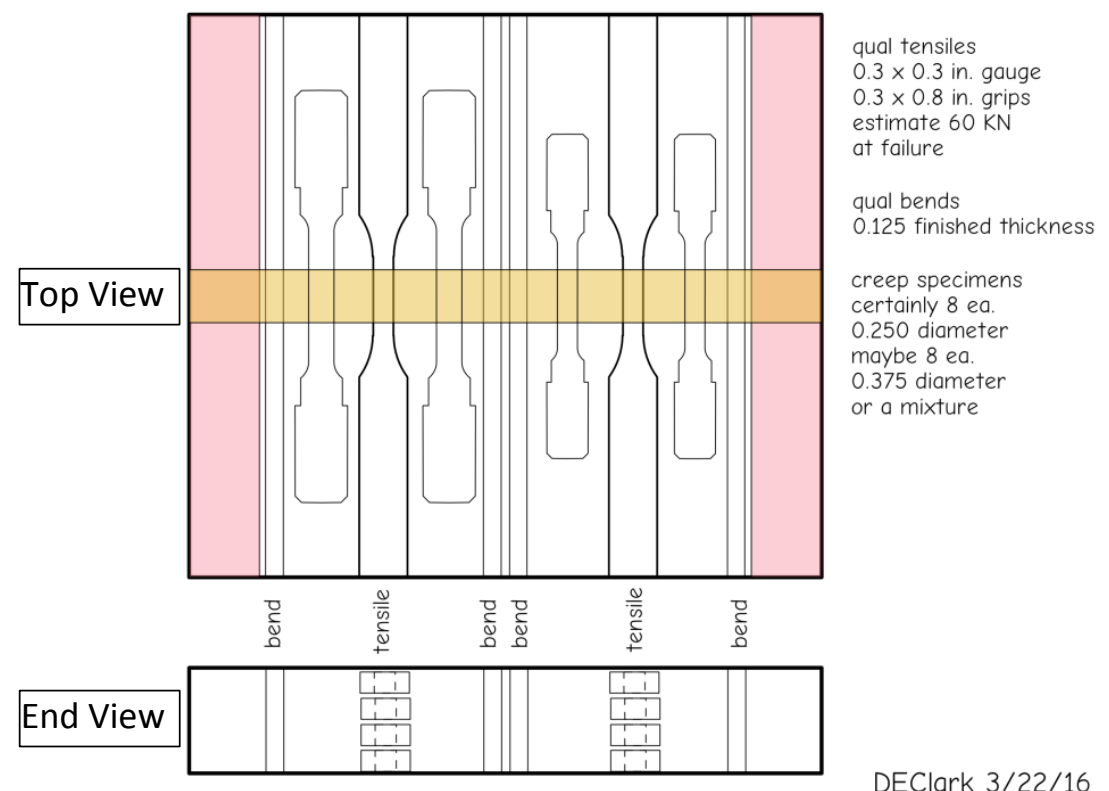




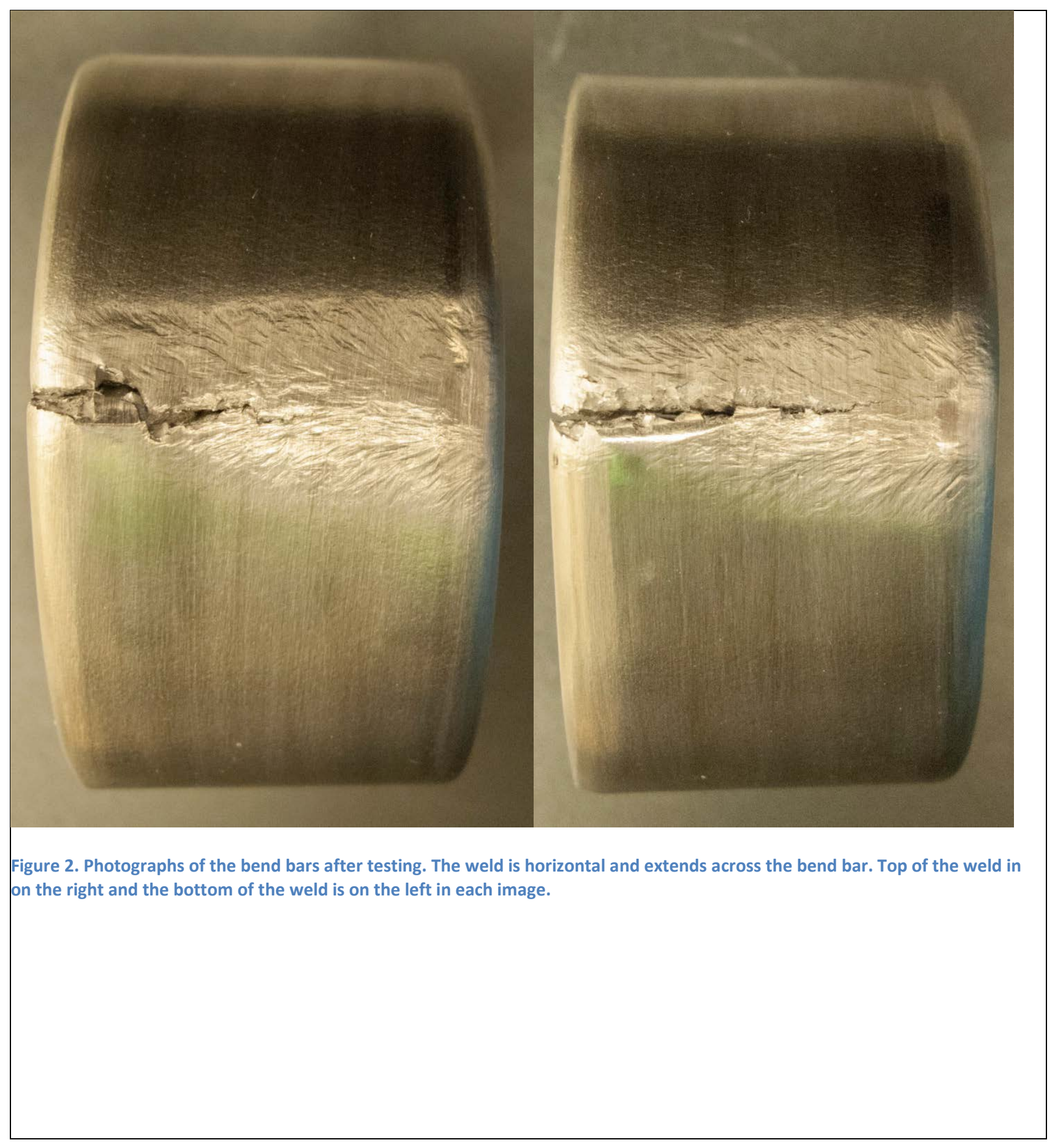



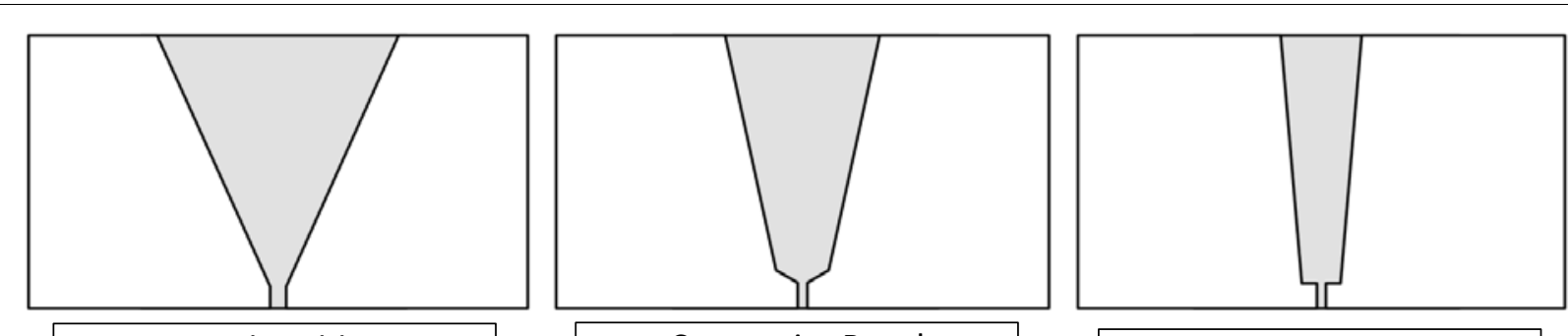

Conventional Weld Design

Composite Bevel

Narrow Groove

Narrow Groove Data: 30" OD, 4" Wall Pipe

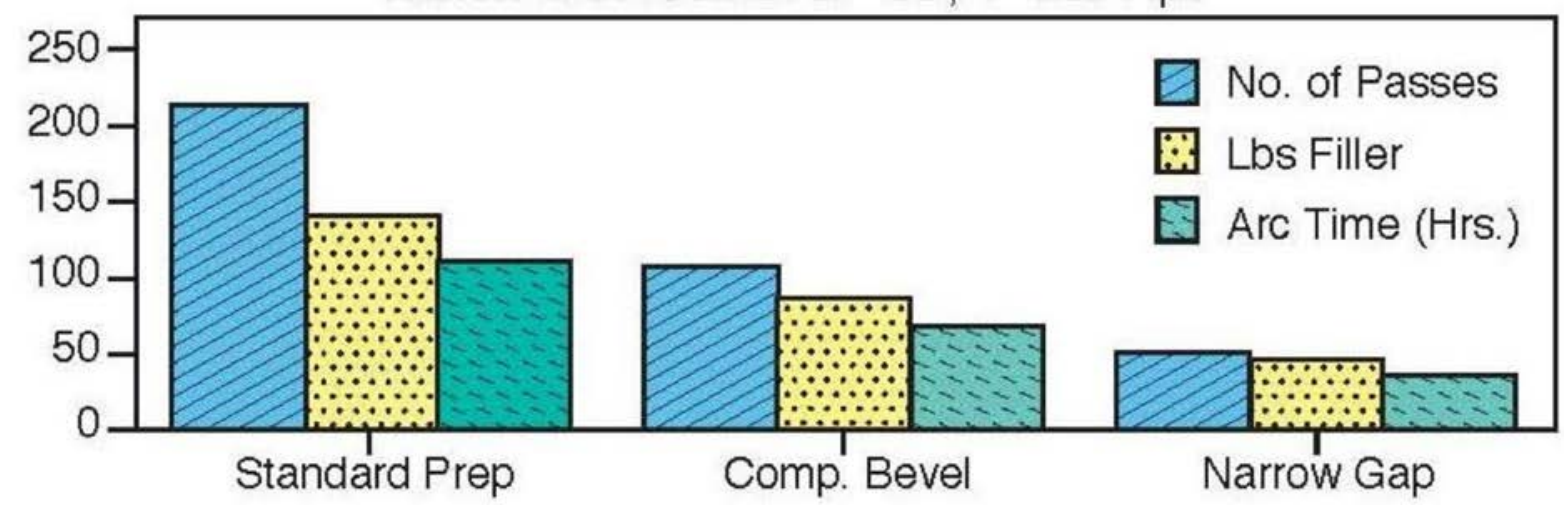

Figure 3. Benefits of the narrow groove/gap weld design.

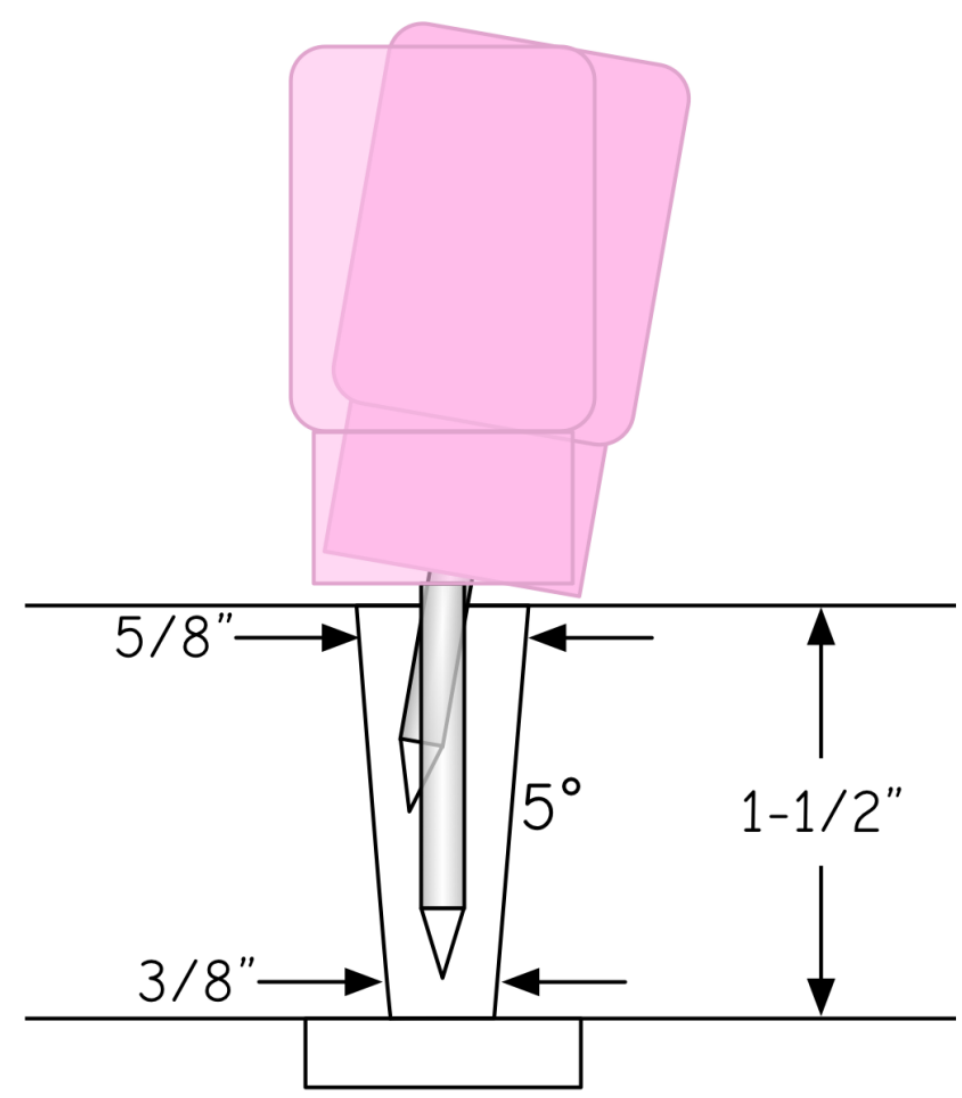




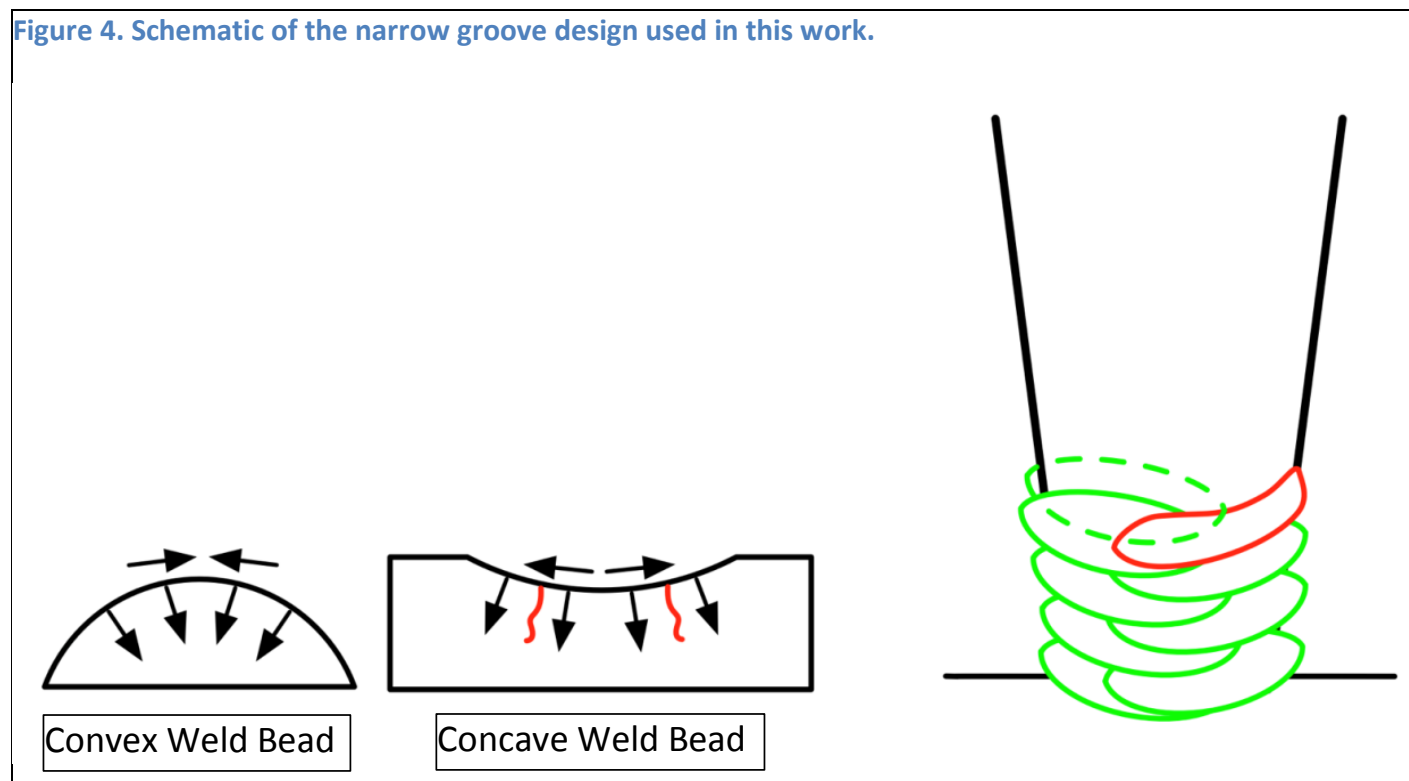

Figure 5. Schematic of the issues caused by a concave weld bead.
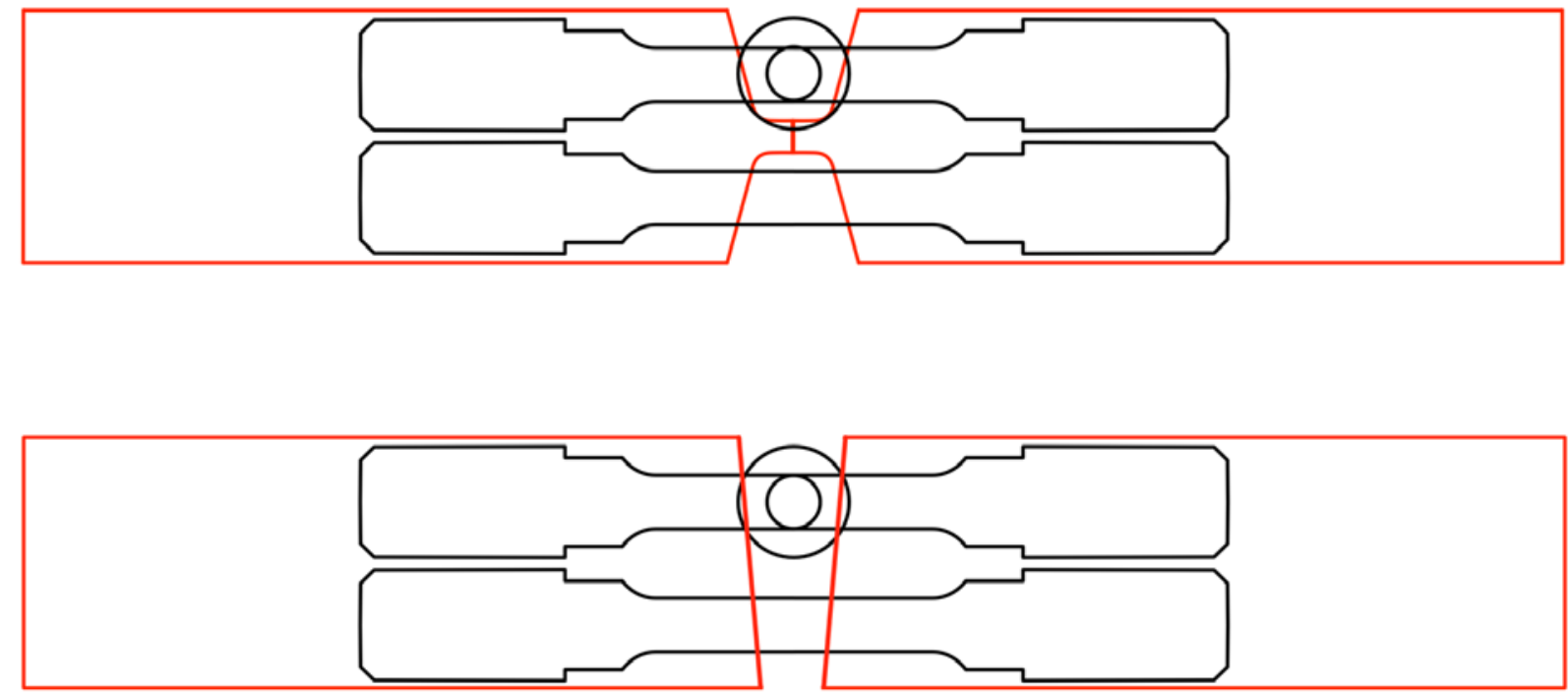

Figure 6. Schematic of the old weld joint design versus the narrow groove design. Schematics of where the creep specimen, cross weld and all-weld metal specimens, will be taken from each groove design are super-imposed on the grooves.

Milestone E, "Characterize Alloy 740H welds"

Remnant material from the narrow groove ASME qualification weld was sectioned and prepared for metallographic observation to characterize the weld microstructure. Figure 7a shows the cross section of the upper part of the weld while Figs. 7b,c and d show defects in the lower portion of the weld. Figure 8 show the longitudinal z-direction (looking down on the weld). This sample was taken from the lower portion of the weld and shows a crack defect.

EBSD was also performed in the longitudinal z-direction sample - the upper portion in the "good" portion of the weld. The results are shown in Fig. 9. The weld is highly textures and appears to be more textured than that found for the Alloy 617 weld in the same orientation. (The visual dominance of red in the center of Alloy 
$740 \mathrm{H}$ weld indicates roughly all the same orientation. The visual dominance is not as great in the 617 weld. Texturing for each weld will be quantified at a later date.)
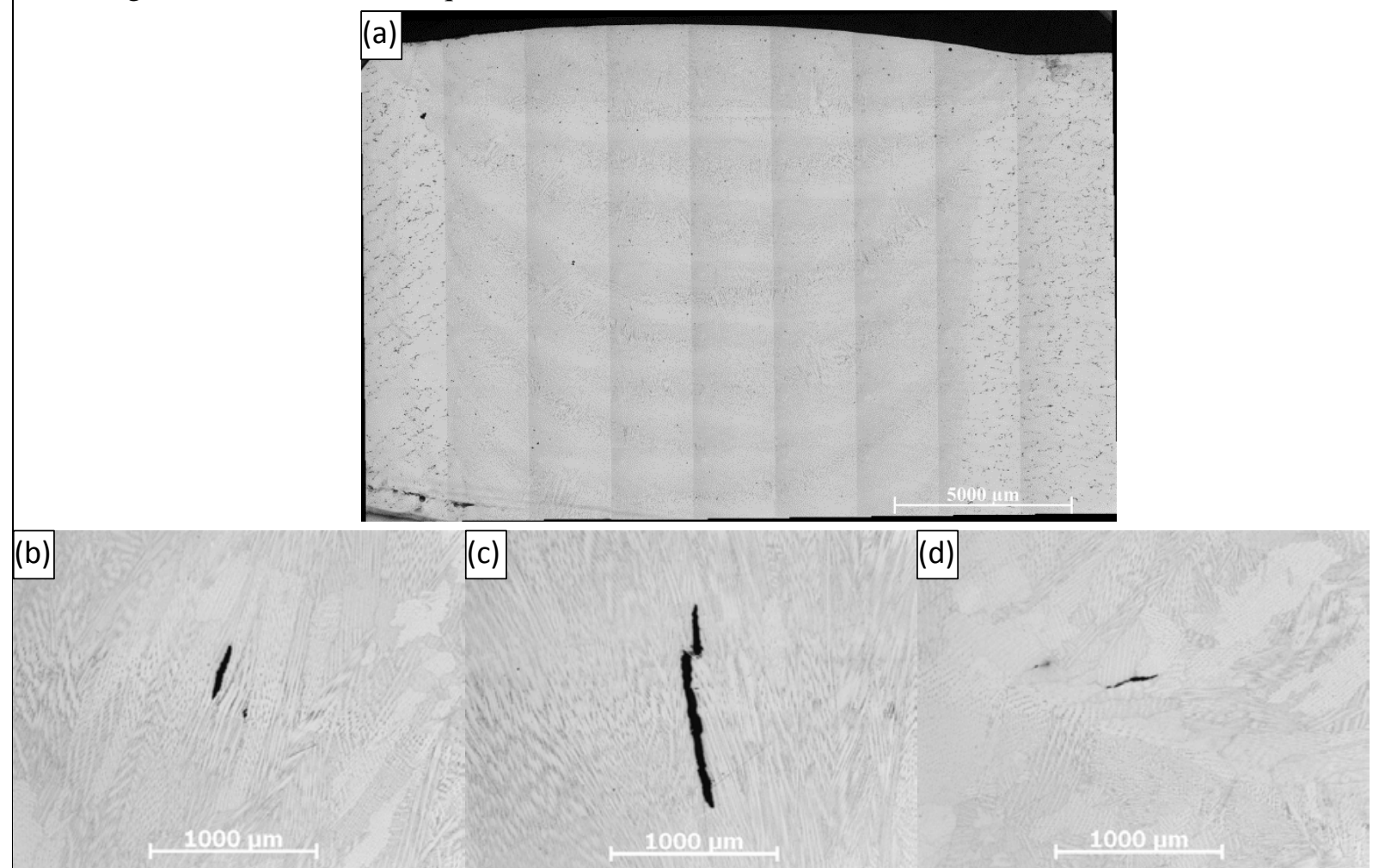

Figure 7. (a) Low magnification overview of the cross section through the upper part of the ASME qualification narrow groove weld while (b)-(d) show weld defects in the lower portion in the weld. 


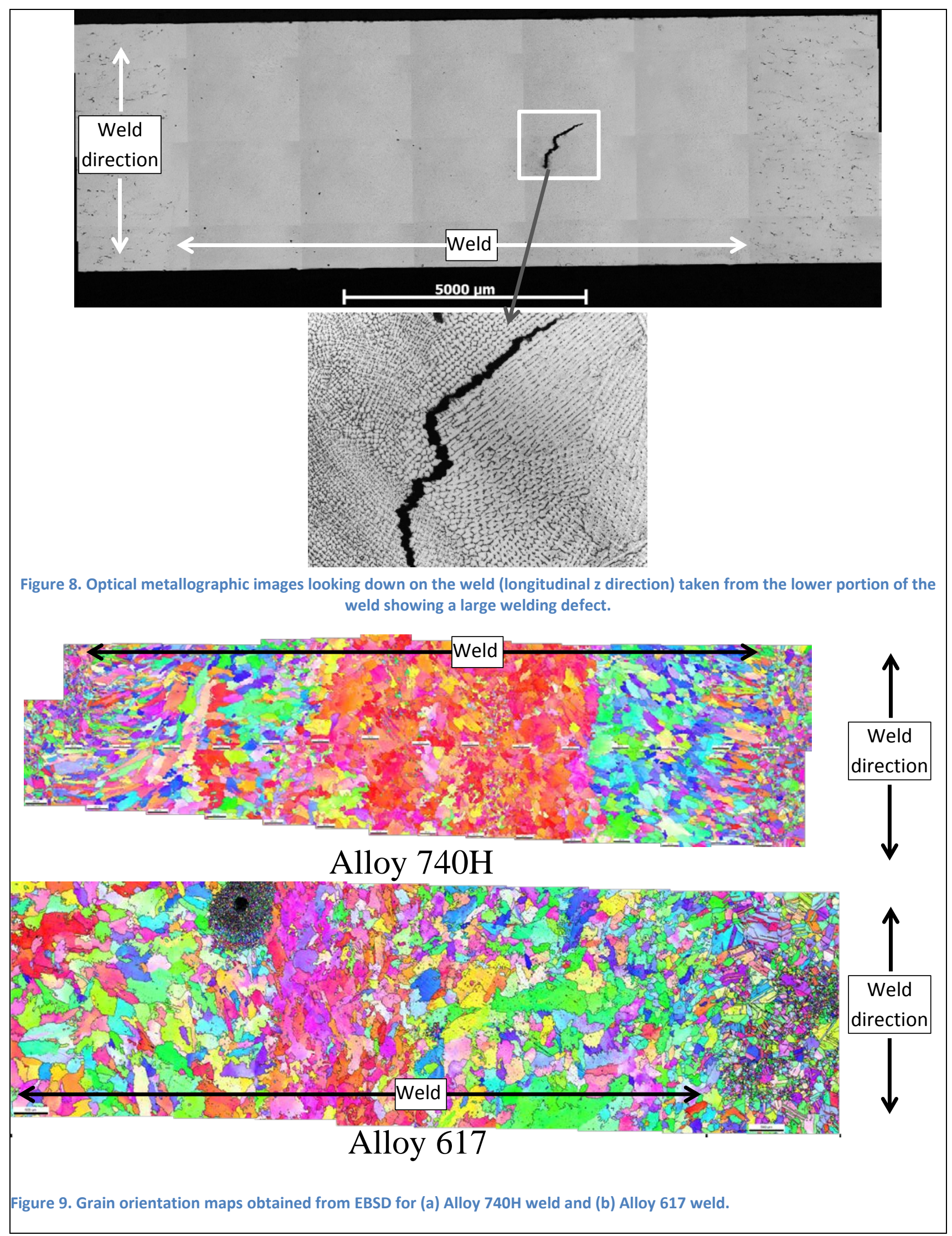


TEM samples have been made for the Alloy 617 weld but have not been compared to the Alloy $740 \mathrm{H}$ weld which are scheduled to be prepared next quarter. TEM is needed for the Alloy $740 \mathrm{H}$ weld to assess the distribution and size of $\gamma$ ' precipitates.

Milestone F, “Creep model development - Stage 1"

\section{Crystal Plasticity Model}

The creep mechanisms currently considered in the dislocation density based crystal plasticity model comprises of dislocation glide, climb and Antiphase Boundary Shearing (APB) of the precipitates. To incorporate these mechanisms in a concurrent manner, the time evolution of plastic deformation gradient $\left(\boldsymbol{F}^{p}\right)$ at a material point is represented as

$\dot{\mathbf{F}}^{y / \mathbf{F}^{p-1}}=\sum_{\alpha} \dot{\gamma}_{g l i d e}^{\alpha} \mathbf{S}_{0}^{\alpha}+\left(1-f_{p p t}\right) \sum_{\alpha} \dot{\gamma}_{c \lim b}^{\alpha} \boldsymbol{N}_{0}^{\alpha}$

where $f_{p p t}$ is the volume fraction of precipitates, $\mathbf{S}_{\mathbf{0}}^{\boldsymbol{\alpha}}$ and $\boldsymbol{N}_{\mathbf{0}}^{\boldsymbol{\alpha}}$ are the glide and climb direction tensors, respectively. The glide rate is further expanded as

$\dot{\gamma}_{g i \text { ide }}^{\alpha}=\left(1-f_{p p^{\prime}}\right) \dot{\gamma}_{\text {matrix }}^{\alpha}+f_{p p^{H}} \dot{\gamma}_{p p^{\prime}}^{a}$

where the contributions from the matrix and precipitate shearing have been considered separately. The glide rate in the matrix follows the Arrhenius equation and is described in detail in [1].

The effect of precipitate on the athermal resistance appearing in the glide rate model is incorporated following

$g_{\text {athermal }}^{\alpha}=\sqrt{\left(\tau_{\text {disloc-disloc }}^{\alpha}\right)^{2}+\left(\tau_{\text {disloc-ppt }}^{\alpha}\right)^{2}}$

where $\tau_{d i s b c-d i s l o c}^{\alpha}$ is described in [1] and $\tau_{d i s l o c-p p t}^{\alpha}$ is from the APB resistance as

$\tau_{\text {disloc-ppt }}^{\alpha}=q_{p p t}\left(\dot{\gamma}_{p p t}\right) \tau_{A P B}^{\alpha}$ 
In Eq. 4, the factor $q$ depends on the shearing rate and is a minimum with respect to a reference-shearing rate. The APB shearing stress, $\tau_{A P B}^{\alpha}$, is obtained from [2] and includes the effect of precipitate size and volume fraction as

$\tau_{A P B}=\frac{2 \gamma_{0}^{3 / 2}}{b^{2}} \sqrt{\frac{f d}{\pi G}}$

where $\gamma_{0}$ is the APB energy, $d$ is the size of the precipitate, $b$ the Burger's vector and $G$ the shear modulus. Based on [3], the model considers that the passage of the leading super-dislocation needs to overcome the APB energy and is the critical event for shearing. Once the leading super dislocation shears the precipitates, a fault is created in the ordered $\mathrm{L} 1_{2}$ structure that is restored by the trailing super dislocation. Piling of dislocations at the precipitate-matrix interface increases the local stress at the interface and facilitates the shearing process. Hence, the velocity of shearing dislocations is represented as

$v_{p p t}^{\alpha}=l a_{0}\left\langle\frac{k\left(\rho_{I}^{\alpha}\right) \tau^{\alpha}}{\tau_{A P B}}-1\right\rangle^{m}$

where $a_{0}$ is the reference shearing rate, $m$ is an exponent, $\boldsymbol{\rho}_{I}^{\alpha}$ is the immobile dislocation density on a slip system and $k\left(\rho_{I}^{\alpha}\right)$ is a dislocation pile-up factor. Finally, the APB shearing rate is based on the Orowan's equation as

$\dot{\gamma}_{p p t}^{\alpha}=\rho_{M}^{\alpha} b v_{p p t}^{\alpha}$

where $\boldsymbol{\rho}_{\boldsymbol{M}}^{\boldsymbol{\alpha}}$ is the mobile dislocation density.

The dislocation climb model is adopted from [4], where the resolved climb stress, $\tau^{\alpha}$, on the edge dislocations

$\tau^{\alpha}=\mathbf{T}^{*}: N_{0}^{\alpha}=\mathbf{T}^{*}: s_{0}^{\alpha} \otimes s_{0}^{\alpha}$ 
modifies the equilibrium vacancy concentration locally at the dislocation core

$c^{*^{\alpha}}=c \exp \left(\frac{V_{m} \tau^{\alpha}}{R T}\right)$

and acts as vacancy source or sink. The velocity of climb is related to the vacancy concentration difference as

$v_{c}^{\alpha}=-\frac{2 \pi D}{b \log \left(r_{\rho} / r_{c}\right)}\left(c^{* \alpha}-c\right)$

where $D$ is the vacancy diffusivity in the dislocation free material, $c$ is the bulk concentration, $r_{c} \sim 4 \mathrm{~b}$ is the dislocation core radius and

$r_{\rho}=\frac{1}{2 \sqrt{\sum\left(\rho_{M}^{\alpha}+\rho_{I}^{\alpha}\right)}}$

is the effect of dislocations on the effective diffusivity. In Eq. (8), $s_{0}^{\alpha}$ is the slip direction. The climb rate in Eq. 1 is defined as

$\dot{\gamma}_{c \lim b}^{(\alpha)}=\left(\rho_{M}^{a}+\rho_{I}^{\alpha}\right) b v_{c}^{a}$

The vacancy concentration in the matrix is evolved following

$\dot{c}=-\nabla j+\sum\left(\rho_{M}^{\alpha}+\rho_{I}^{\alpha}\right) b v_{c}^{\alpha}$ 
where $j$ is the vacancy flux and the second term is due to the cumulative effect of vacancy absorption or emission to cause climb. It is assumed in Eq. (13) that if climb is occurs on 2 slip systems at the same rate where one acts as source and the other as sink, the net vacancy concentration in the bulk is preserved.

\section{Numerical Examples}

\section{2.a Dislocation glide model}

A cube of size $75 \times 75 \times 75 \mu \mathrm{m}^{3}$ with 27 grains is used to verify the dislocation density model without the climb and APB shear component. The volume is displaced on the top surface and symmetric boundary conditions are used to restrain the rigid body motion. Random orientations are assigned to every grain as shown in Fig. 1(a). The volume averaged stress-strain response is shown in Fig. 1(b).

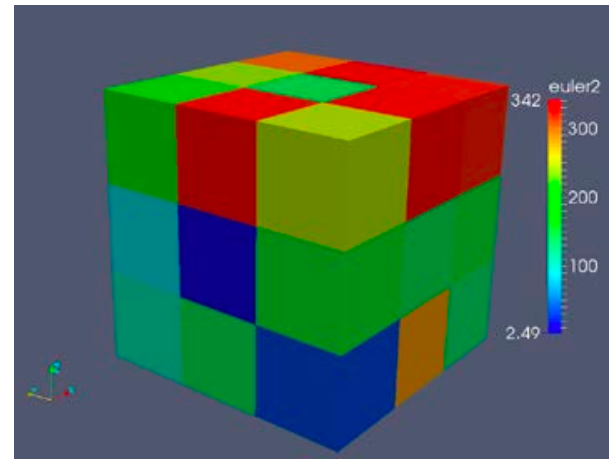

(a)

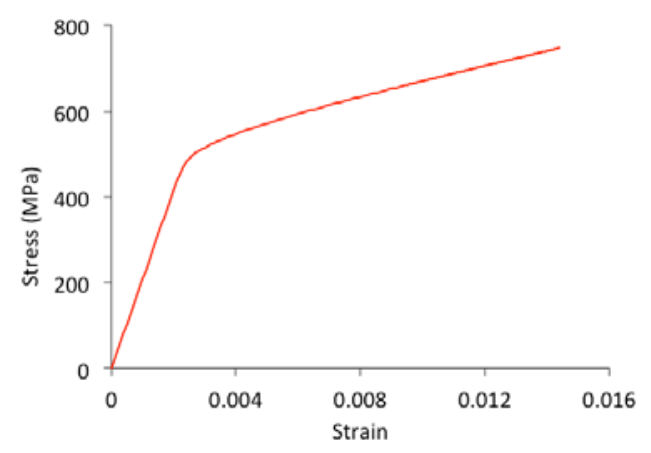

(b)

Figure 1: (a) Euler angle component $\theta$ in the representative polycrystalline microstructure. (b) Volumeaveraged stress-strain response.

The effect of grain orientation and strain compatibility leads to heterogeneous distribution of stress and plastic strain as shown in the material line plot in Fig. 2.
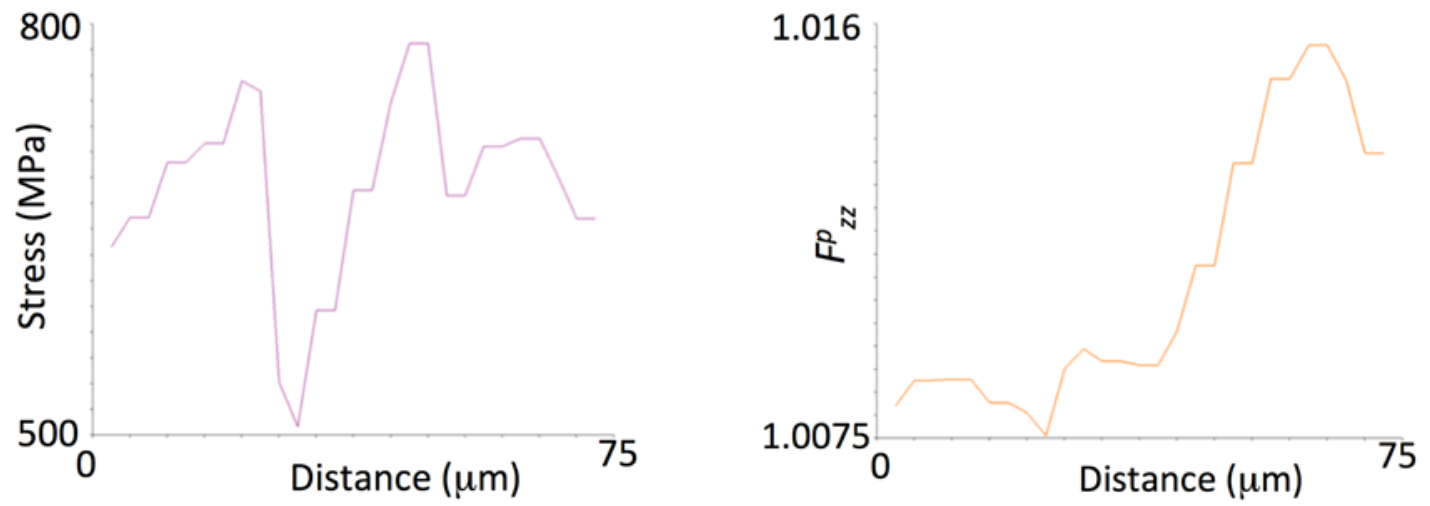


\section{(a)}

(b)

Figure 2: Response along a material line at 0.015 macroscopic strain: (a) Stress and (b) plastic deformation gradient component normal to loading direction.

\section{2.b Dislocation glide and climb model}

The combined dislocation climb and glide model is verified using a single crystal of size $1 \mathrm{x} 1 \mathrm{x} 1 \mu \mathrm{m}^{3}$. The unit cube is subjected to follower pressure loads at different temperatures. For an applied compressive stress of $500 \mathrm{MPa}$, the creep strain and mobile dislocation density evolution on (11-1)[011] system is shown in Fig. 3. As can be seen from the figure, with increasing temperature the primary creep mechanism is glide dominated. This is due a larger thermal activation for glide at higher temperatures and the faster kinetics of gliding dislocations. A similar behavior is observed in Fig. 4 at different stress levels and temperature of 700 K. For both the scenarios, glide dominates the initial stages of creep followed by climb at much larger times.

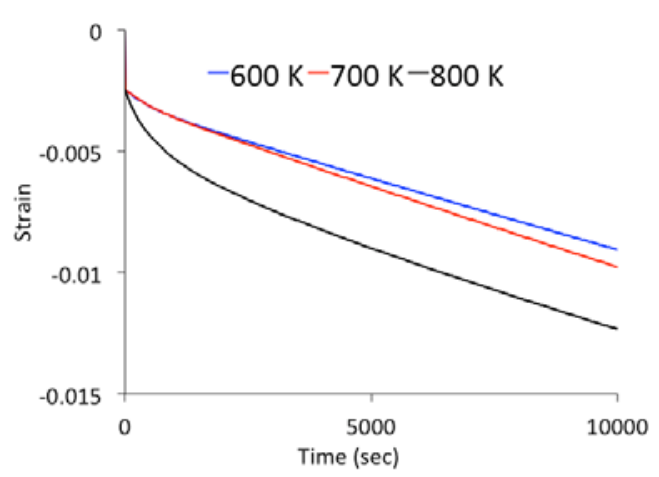

(a)

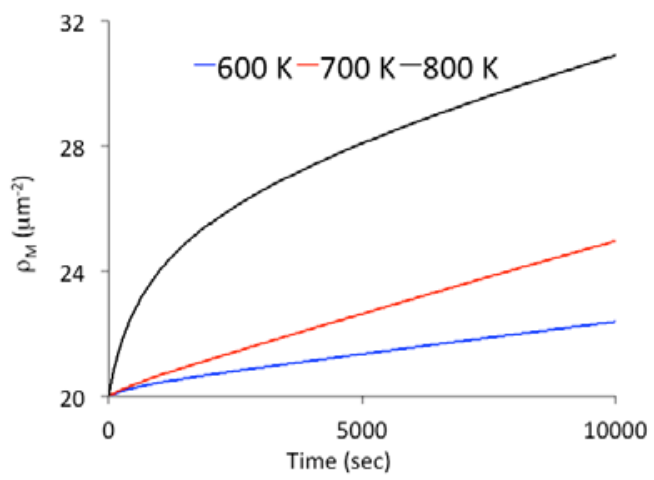

(b)

Figure 3: Single crystal creep at stress $500 \mathrm{MPa}$ and varying temperature. (a) Creep strain; (b) Mobile dislocation density (11-1)[011] system.

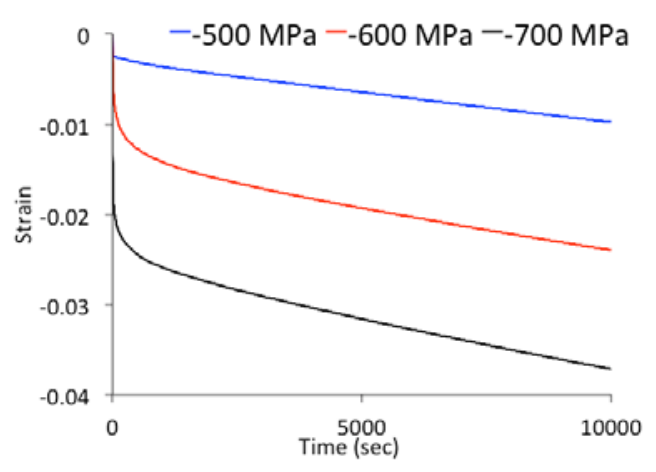

(a)

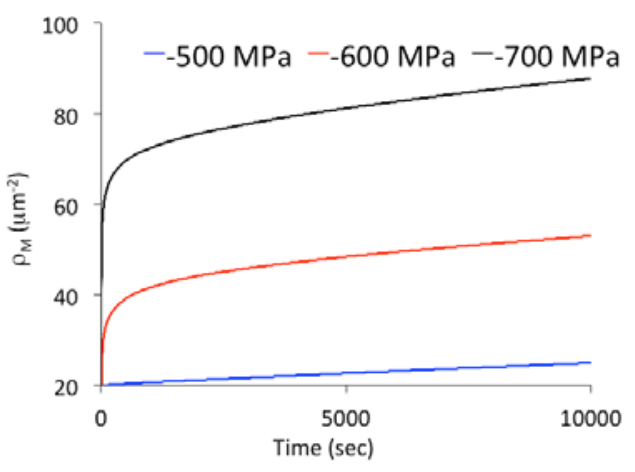

(b)

Figure 4: Single crystal creep at temperature 700K and varying stresses. (a) Creep strain; (b) Mobile dislocation density (11-1)[011] system. 
2.c Dislocation glide and APB shear model

The model is verified by uniaxially displacing the unit cube described above, on the top surface. A comparison is made with the scenario where precipitates are absent.

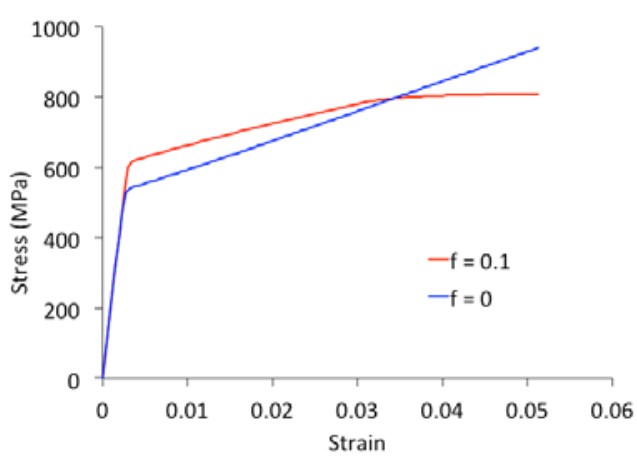

(a)

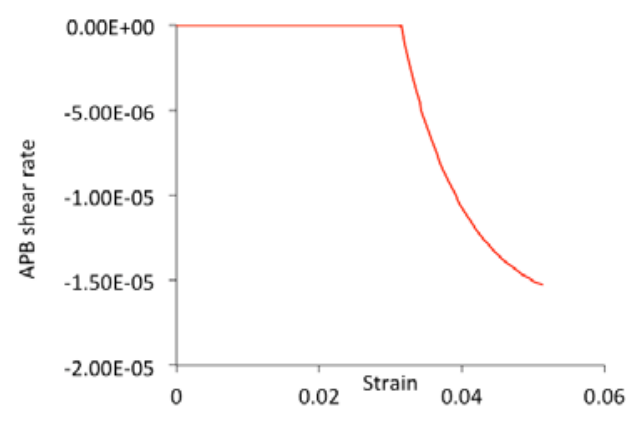

(b)

Figure 5: Comparison of glide and glide combined with APB shear. (a) Stress-strain, (b) APB shear rate on (11-1)[011].

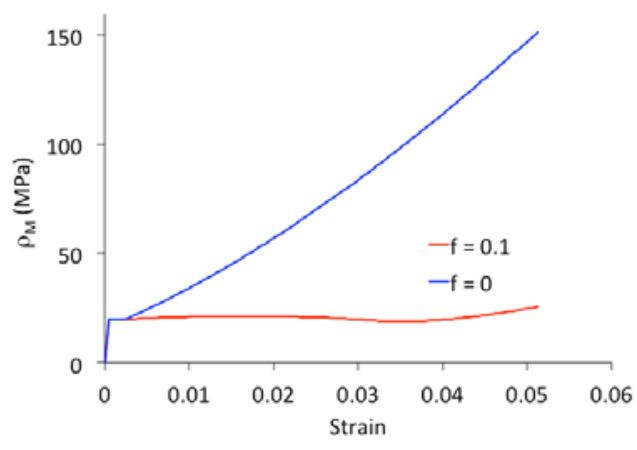

(a)

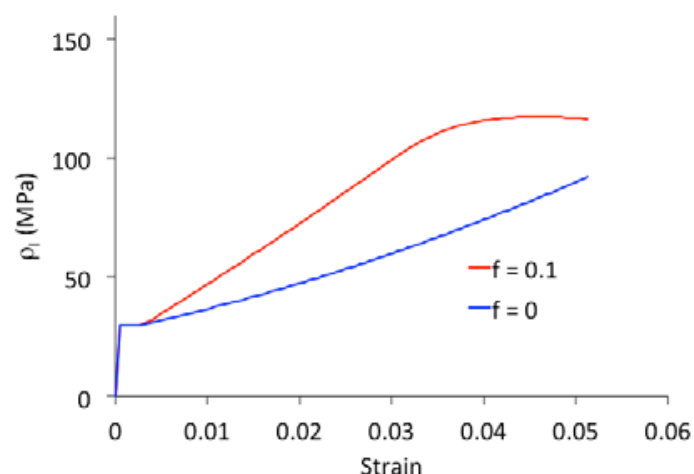

(b)

Figure 6: Comparison of glide and glide combined with APB shear. (a) Mobile, and, (b) Immobile densities on (11-1)[011] system. 
As can be observed from both the figures, the yield stress is higher for the material with precipitate due to the higher athermal resistance. Also, the presence of precipitates reduces the trapping distance, thus lowering the strain hardening capacity. Finally, the APB shear is delayed and initiates once a critical immobile dislocation density is reached.

\section{Crystal Plasticity model with diffuse interface}

A diffused crystal plasticity approach is currently being developed in MOOSE where the grains are represented by order parameters. A volume-averaged stress is computed at material points where multiple phases exist. A comparison with the sharp interface model for a bicrystal with uniaxial displacement is shown in Fig. 7.

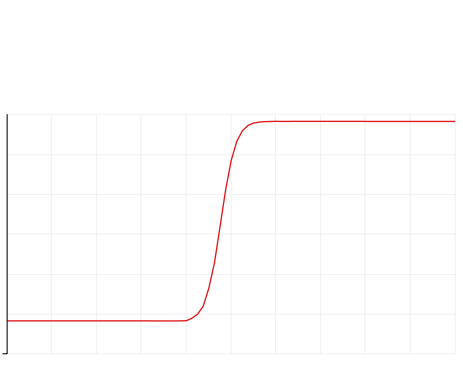

(a)

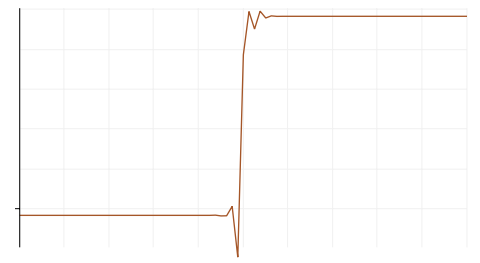

(b)

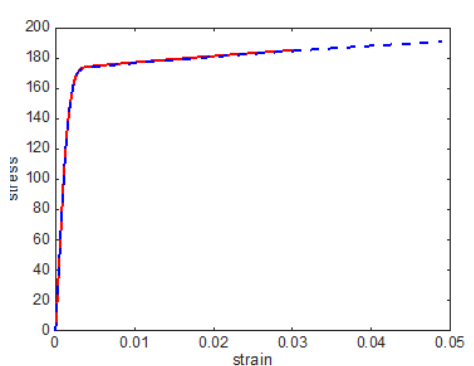

(c)

Figure 7: Stress-strain along a material line - (a) diffused interface and (b) sharp interface. (c) Comparison of volume averaged stress-strain.

\section{References:}

[1] P. Chakraborty, S. B. Biner , "Crystal plasticity modeling of irradiation effects on flow stress in pure-iron and ironcopper alloys”, Mechanics of Materials, 101, 2016 ,71-80.

[2] J. Zhang, T. Jin, Y. Xu, Z. Hu, “Antiphase Boundary Strengthening in a single crystal Nickel-base Superalloy”, J. Mater. Sci. Tech., 18(2), 2002, 159-162.

[3] T. M. Pollock and A. S. Argon, Creep resistance of CMSX-3 Nickel base superalloys single crystal”, Acta Metall. Mater, 40(1), 1991, 1-30.

[4] M.G.D. Geers, M. Cottura, B. Appolaire, E.P. Busso, S. Forest, A. Villani, “Coupled glide-climb diffusion-enhanced crystal plasticity”, Journal of the Mechanics and Physics of Solids, 70, 2014, 136-153. 
ISSUES

The expected completion dates for Milestones D \& E were revised based on unexpected difficulties in welding Alloy $740 \mathrm{H}$. Weld material has now been made and the characterization has begun. A path forward on welding has been developed and all the welding should be completed by early next quarter.

\begin{tabular}{|l|l|}
\hline Report Prepared By & Date \\
\hline Thomas M. Lillo & $08 / 03 / 2016$ \\
\hline
\end{tabular}

